\title{
Ultrasound guided fine needle aspiration cytology: a sensitive diagnostic tool for diagnosis of intra-abdominal lesions
}

\author{
Islam $\mathrm{T}^{1}$, Hossain $\mathrm{F}^{2}$, Rumpa $\mathrm{AP}^{3}$, Sikder $\mathrm{NH}^{4}$, Bhuiyan $\mathrm{MA}^{3}$, Karim $\mathrm{E}^{5}$, Hossain $\mathrm{A}^{6}$ \\ ${ }^{1}$ Radiologist, Sylhet Shaheed Shamsuddin Ahmed Hospital, ${ }^{2}$ Department of Radiology and Imaging Sylhet \\ Women's Medical College \& Hospital, ${ }^{3}$ Department of Radiology \& Imaging, Sylhet MAG Osmani Medical \\ College \& Hospital, ${ }^{4}$ Department of Neurology, Northern International Medical College \& Hospital, Dhaka, \\ ${ }^{5}$ Professor of Radiology \& Imaging, Bangabandhu Sheikh Mujib Medical University, Dhaka, ${ }^{6}$ Department of \\ Pathology, Jalalabad Ragib-Rabeya Medical College and Hospital, Sylhet.
}

Email:tariqul33@gmail.com

\begin{abstract}
Ultrasound guided fine needle aspiration cytology is widely accepted as a safe diagnostic procedure in various neoplastic and non-plastic disorders. This study was conducted to determine the usefulness and diagnostic accuracy of ultrasound guided fine needle aspiration cytology in the diagnosis of intraabdominal lesions. This cross sectional study was conducted in the Department of Radiology and Imaging, Sylhet MAG Osmani Medical College Hospital, Sylhet, Bangladesh during the period of June 2007 to June 2009. A total 78 patients with intra abdominal lesions were included in this study. Fifty nine $(75.6 \%)$ were males and $19(24.4 \%)$ were females. Out of total aspirates $29(37.2 \%)$ were categorized as benign, 41(52.6\%) were malignant and $8(10.3 \%)$ were non-representative, as it contained only blood. Most of the benign lesions were liver abscess 19(24.4\%). A diagnosis of primary malignancy was established in $26(33.3 \%$ ) and that of secondary in $15(19.2 \%)$. The results showed a sensitivity of $89.7 \%$. Ultrasound guided fine needle aspiration cytology is a sensitive diagnostic tool in a wide spectrum of intra-abdominal neoplastic and non-neoplastic disorders. It is a simple, safe, rapid and inexpensive technique.
\end{abstract}

\section{Introduction}

The evaluation of deep, non-palpable masses or focal lesions involving abdominal sites is often difficult. Distinction between malignant and nonmalignant lesions and particularly inflammatory lesions is vital for patient management. Clinical presentations such as organomegaly, weight loss, anaemia and jaundice are usually associated with malignancy but can be misleading at times. Nonneoplastic conditions such as pyogenic abscesses and tuberculosis can produce focal lesions that may be mistaken for malignancy. Although distinction between malignant and non-malignant lesions is often suspected from imaging techniques, the increasing use and sensitivity of radiological techniques has led to the identification of relatively small lesions, which require the use of image guidance for reliable targeting ${ }^{1}$, but the diagnosis is dependent on obtaining an accurate tissue diagnosis, usually by percutaneous sampling ${ }^{2}$.

Fine needle aspiration cytology is a wellestablished diagnostic technique and is increasing in popularity as a means of diagnosing mass lesions in intra-abdominal organs. With use of radiologic guidance for needle placement, this technique is an effective way to obtain diagnostic material for rapid and accurate diagnosis ${ }^{2-5}$.

Although computerized tomography/ real-time ultrasonographically guided fine needle aspiration of abdominal organs is practiced extensively throughout the world ${ }^{6}$.

Ultrasound guided fine needle aspiration cytology is a rapid, economical and safe diagnostic procedure without any radiation hazard ${ }^{7}$.

Ultrasound guided fine needle aspiration cytology was not extensively practiced in Bangladesh. This study was designed to evaluate the accuracy of Ultrasound guided fine needle aspiration cytology in the diagnosis of intra- abdominal lesions.

\section{Material and Methods}

This cross sectional study was conducted in the Department of Radiology and Imaging, Sylhet MAG Osmani Medical College \& Hospital, Sylhet, Bangladesh during the period of June 2007 to June 2009. A total of 78 Ultrasound guided fine needle aspiration cytology (using Toshiba, 3.5 MHz with curvilinear probe) of various intra-abdominal 
lesions were performed. These included lesions of liver (60), gall bladder (3), kidneys (2), lymph nodes (4), epigastric mass (4), psoas mass (2), suprarenal gland (1), lower abdominal mass (1), and bowel (1). The main indication of ultrasound guided fine needle aspiration cytology was various abdominal lesions with abnormal ultrsonographic or computed tomographic findings. The reason for the fine needle aspiration cytology, the procedure itself and the absence of any significant risks were explained to the patient before starting the fine needle aspiration cytology. No pre-procedural preparation was required. The preferred and easiest approach was through the anterior abdominal wall, but posterior or flank approaches were used if they were shorter. While localizing the lesion we imaged the lesion in horizontal plane and to reduce refraction error the transducer was rotated clock wise for 90 degree to localize the lesion at vertical plane. Main concept was to localize the lesion from same skin point in horizontal and vertical plane and then the target point of needle insertion was selected.

Fine needle aspiration was performed like any routine intramuscular injection, dispensing with gloves, masks, sterile draping and local anaesthesia. Gloves were occasionally needed for estabilising the needle shaft during advancement of a long flexible needle. The aspiration sites were prepared with a topical antiseptic. For superficial lesions a 23 gauge needle attached to a $10 \mathrm{cc}$ disposable syringe was used and for the deeper lesions a 23 gauge spinal needles (spinocane) were also used. After inserting the needle into the lesion, strong suction was applied and the needle tip was moved in and out by about $5 \mathrm{~mm}$, (once it had entered the lesion) and after withdrawing the needle smears were prepared and slides were sent to the cytopathologists in a Koplin's jar containing 95\% alcohol. Whenever required, care was taken to obtain material from the most solid portion of the lesion.

Of the 78 fine needle aspiration, the smallest sized lesion was $1 \mathrm{~cm}$ in diameter. The majority were greater than $5 \mathrm{~cm}$ in size.

\section{Results}

Seventy-eight patients with inta-abdominal lesions were included in this study of which 59 (75.6\%) were males and $19(24.4 \%)$ were females. The age of the patients was ranging 1.5 years to 82 years with the mean \pm SD $(45.22 \pm 17.59)$. Distribution of the age of the patients was shown in Table-I.
Table I: Distribution of the age of the patients $(n=78)$

\begin{tabular}{lcc}
\hline Age Group (in yrs.) & Frequency & Percentage \\
\hline $01-09$ & 3 & 3.8 \\
$10-19$ & 2 & 2.6 \\
$20-29$ & 10 & 12.8 \\
$30-39$ & 12 & 15.4 \\
$40-49$ & 11 & 14.1 \\
$50-59$ & 19 & 24.4 \\
$60-69$ & 13 & 16.6 \\
70 and above & 8 & 10.3 \\
\hline Total & 78 & 100.0 \\
\hline
\end{tabular}

The most common clinical presentations were abdominal mass (70.5\%), anorexia (66.7\%), anaemia (56.4\%), weight loss (48.7\%), hepatomegaly $(44.9 \%)$, abdominal pain $(43.6 \%)$. Distribution of patients by clinical presentation was shown in Table-II.

Table II: Clinical presentation $(\mathrm{n}=78)$

\begin{tabular}{lcc}
\hline Clinical presentation & Frequency* & Percentage \\
\hline Abdominal pain & 34 & 43.6 \\
Fever & 26 & 33.3 \\
Anorexia & 52 & 66.7 \\
Weight loss & 34 & 48.7 \\
Anaemia & 44 & 56.4 \\
Jaundice & 19 & 24.4 \\
Constipation & 15 & 19.2 \\
Diarrhoea & 21 & 26.9 \\
Abdominal mass & 55 & 70.5 \\
Hepatomegaly & 35 & 44.9 \\
\hline
\end{tabular}

*Total Frequency exceeds 78 and percentage exceeds 100 due to multiple clinical presentation in most of the cases.

Liver mass was the most common lesions of fine needle aspiration cytology 60(76.9\%). Distribution of the site of abdominal lesions was shown in Table-III.

Table III: Distribution of the site of abdominal lesions $(\mathrm{n}=78)$

\begin{tabular}{lcc}
\hline Organ involved & Frequency & Percentage \\
\hline Liver mass & 60 & 76.9 \\
Gall bladder mass & 3 & 3.8 \\
Lymph node & 4 & 5.1 \\
Renal mass & 2 & 2.6 \\
Epigastric mass & 4 & 5.1 \\
Lower abdomen mass & 1 & 1.3 \\
Bowel mass (RIF) & 1 & 1.3 \\
Psoas mass & 2 & 2.6 \\
Suprarenal mass & 1 & 1.3 \\
\hline Total & 78 & 100.0 \\
\hline
\end{tabular}

Out of total aspirates $29(37.2 \%)$ were categorized as benign, 41(52.6\%) were malignant and 8(10.3\%) were non-representative, as it contained only blood. The results showed a sensitivity of $89.7 \%$. Distribution of patients on cytological diagnosis was showed in Table-IV.

Table IV: Cytological categories

\begin{tabular}{lcc}
\hline Diagnosis & Frequency & Percentage \\
\hline Benign & 29 & 37.2 \\
Malignant & 41 & 52.6 \\
Non-representative & 8 & 10.3 \\
\hline Total & 78 & 100.0 \\
\hline
\end{tabular}


Table V: Distribution of patients on Cytological diagnosis $(n=78)$

\begin{tabular}{|c|c|c|c|c|}
\hline \multicolumn{3}{|c|}{ Cytological diagnosis } & Frequency & Percentage \\
\hline \multirow{5}{*}{\multicolumn{2}{|c|}{. }} & Liver abscess & 19 & 24.4 \\
\hline & & Psoas abscess & 2 & 2.6 \\
\hline & & Tuberculosis & 5 & 6.4 \\
\hline & & Focal nodular hyperplasia & 2 & 2.6 \\
\hline & & Hepatic adenoma & 1 & 1.3 \\
\hline \multirow{7}{*}{ 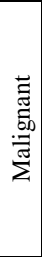 } & \multirow{5}{*}{ 胥 } & Adenocarcinoma & 12 & 15.4 \\
\hline & & Hepatocellular Carcinoma & 11 & 14.1 \\
\hline & & Hepatoblastoma & 1 & 1.3 \\
\hline & & Neuroblatoma & 1 & 1.3 \\
\hline & & Wilm's tumor & 1 & 1.3 \\
\hline & \multirow{2}{*}{ 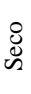 } & $\begin{array}{l}\text { Metastatic } \\
\text { Adenocarcinoma }\end{array}$ & 14 & 17.9 \\
\hline & & Small cellcarcinoma & 1 & 1.3 \\
\hline \multicolumn{3}{|c|}{ Non-representative (Failure) } & 8 & 10.3 \\
\hline \multicolumn{3}{|c|}{ Total } & 78 & 100.0 \\
\hline
\end{tabular}

Most of the benign lesions were liver abscess 19(24.4\%), others benign lesions were tuberculosis $5(6.4 \%)$, psoas abscess and focal nodular hyperplasia each comprises $2(2.6 \%)$; and hepatic adenoma $1(1.3 \%)$.

A diagnosis of primary malignancy was established in $26(33.3 \%)$ and that of secondary in $15(19.2 \%)$ of cases. The primary malignancies were adenocarcinoma 2(15.4\%), hepatocellular carcinoma 11(14.1\%) and hepatoblastoma, neuroblastoma and Wilm's tumour each comprised $1(1.3 \%)$. The secondary malignancies were mostly metastatic adenocarcinoma $14(17.9 \%)$ and only $1(1.3 \%)$ was metastatic small cell carcinoma (Table-V).

Non-representative sample or failure was in $8(10.3 \%)$ of the sample; and $6(7.7 \%)$ in liver mass and $2(2.6 \%)$ in the epigastric mass.

No significant complications were observed except minimal discomfort at the time of needle puncture.

\section{Discussion}

The confirmation of diagnosis is of immense importance for rapid and appropriate planning of management of cases. Differentiation between nonmalignant and malignant disease is at times vital, to avoid an exploratory laparotomy, especially in advanced unresectable malignant cases.

Fine-needle aspiration cytology is increasing in popularity as a means of diagnosing mass lesions in intra-abdominal organs. With use of radiologic guidance for needle placement, this technique is an effective way to obtain diagnostic material. In selected instances, fine needle aspiration is superior to core-needle or open biopsy in terms of cost, procedure-associated morbidity, and timeliness of diagnosis.
In this study suction technique was used in all cases to obtain the materials for cytopathology and it was possible to obtain sufficient material for diagnosis in $89.7 \%$ of cases. Our results compare favourably with reported success rates of $86-96 \%$ from various studies using ultrasound guidance and computerized tomography guidance for fine needle aspiration cytology $y^{6,8-15}$.

In addition, the cost effectiveness and rapidity of ultrasound guided fine needle aspiration cytology, and non-availability of computed tomography, coupled with the higher incidence of advanced malignancy due to public awareness, overburdened surgical units with meager resources, establishes this procedure as indispensable for cancer management in developing countries. One of the most interesting features of this series is the high yield and uncomplicated nature of aspiration performed at various sites.

The impact of on-site cytopathological examination of breast, thyroid, head and neck masses, lung lesions, and lymph nodes has been well established $^{15-17}$. However, on-site cytopathological examination minimizes the sampling errors. On-site cytopathological examination was not available in the study place and sampling error may be more for this reason and this was one of the study limitations.

Thus, this series substantiates the accuracy of (real time) ultrasound guided fine needle aspiration cytology in a wide spectrum of abdominal and pelvic neoplastic and non-neoplastic disorders. No other diagnostic technique can be so simple, safe, rapid and inexpensive while giving such valuable information as ultrasound guided fine needle aspiration cytology. Moreover this procedure helps in decreasing use of hospital resources apart from reducing patient discomfort, morbidity and an increase in timeliness of diagnosis. Adequate sampling, experience and caution in interpreting the aspirate and a close working relationship between clinician, sonologists and cytopathologists are factors essential for its success.

\section{References}

1. Stewart CJR, Coldewey J, Stewart IS. Comparison of fine needle aspiration cytology and needle core biopsy in the diagnosis of radiologically detected abdominal lesions. J Clin Pathol 2002; 55: 93-97.

2. Sheikh M, Sawhney S, Dey P, AI-Saeed O, Behbehani A. Deep-seated thoracic and abdominal masses: Usefulness of ultrasound and computed tomography guidance in fine needle aspiration cytology diagnosis. Australasian Radiology 2000; 44: 155-60. 
3. Dodd LC, Mooney EE, Layfield LJ, Nelson RC. FineNeedle Aspiration of the Liver and Pancreas: A Cytology Primer for Radiologists. Radiology 1997; 203:1-9.

4. Dey P, Radhika S, Kochhar S, Rajwanshi A. Fine needle aspiration cytology of pancreas. Indian J Pathol Microbiol 1994; 37: 269-74.

5. Reddy VB, Gattuso P, Abraham KP, Moncada R, Casteli MJ. Computed tomography-guided fine needle aspiration biopsy of deep-seated lesions-a four-year experience. Acta Cytologica 1991; 35: 753-6.

6. Das DK, Tripathi RP, Bhambhani S, Chachra, KL, Sodhani P, Malhotra V. Ultrasound-Guided FineNeedle Aspiration Cytology Diagnosis of Gallbladder Lesions: A Study of 82 Cases. Diagn. Cytopathol. 1998; 18: 258-64.

7. Ikezoe J, Morirnoto S, Arisawa J, Takashima S, Kozuka, T, Nakahara K. Percutaneous Biopsy of Thoracic Lesions: Value of Sonography for Needle Guidance. AJR 1990; 154: 1181-5.

8. Fisher AJ, Paulson EK, Sheafor DH, Simmons CM, Nelson RC. Small lymph nodes of the abdomen, pelvis, and retroperitoneum: Usefulness of sonographically guided biopsy. Radiology 1997; 205: 185-90.

9. Yu SCH, Metreweli C, Lau WY, Leung WT, Liew CT, Leung NWY. Safety of percutaneous biopsy of hepatocellular carcinoma with an 18 gauge automated needle. Clin Radiol 1997; 52: 907-11.

10. Memel DS, Dodd GD III, Esola CC. Efficacy of sonography as a guidance technique for biopsy of abdominal, pelvic and retroperitoneal lymph nodes. AJR 1996; 167: 957-62.

11. Tikkakoski T, Siniluoto T, Ouikainen A et al. Ultrasound guided aspiration cytology of enlarged lymph nodes. Acta Radiol 1991; 32: 53-6.

12. Stanley JH, Fish GD, Andriole JG et al. Lung lesions: Cytologic diagnosis by fine needle biopsy. Radiology 1987; 162: 389-91.

13. Sundaram M, Wolverson MK, Heiberg E, Pilla T, Vas WG, Shields JG. Utility of CT-guided abdominal aspiration procedures. Am J Radiol 1982; 139:1111-15.

14. Stewart CJ, Duncan JA, Farquharson M, Richmond J. Fine needle aspiration cytology diagnosis of malignant lymphoma and reactive lymphoid hyperplasia. J Clin Pathol 1998; 51: 197-203

15. Layfield LJ, Bentz JS, Gopez EV. Immediate on-site interpretation of fine needle aspiration smears. A cost and compensation analysis. Cancer 2001; 93: 319-22.

16. Guo Z, Kurtycz DF, Salem R, De Las Casas LE, Caya JG, Hoerl HH. Radiologically guided percutaneous fineneedle aspiration biopsy of the liver: retrospective study of 119 cases evaluating diagnostic effectiveness and clinical complications. Diagn Cytopathol 2002; 26: 283-9.

17. Klapman JB, Logrono R, Dye CE, Waxman I. Clinical impact of on-site cytopathology interpretation of endoscopic ultrasound-guided fine needle aspiration. Am J Gastroenterol 2003; 98: 1289-94. 